\title{
UPDATED METHODS TO AGE THE AUSTRALIAN LUNGFISH: REPLY TO KEMP (2015)
}

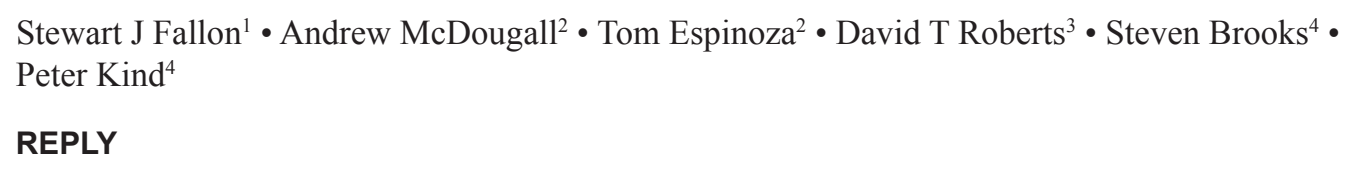

\section{REPLY}

Kemp's comments in this issue (Kemp 2015) have raised several issues regarding dating Australian lungfish (Neoceratodus forsteri) using bomb radiocarbon in their scales (James et al. 2010). The James et al. (2010) publication represented a pilot study in which the feasibility of using bomb ${ }^{14} \mathrm{C}$ in lungfish scales could provide an age for an individual fish. Kemp's first issue relates to nomenclature regarding the different parts of the scale. This nomenclature was detailed in Kemp (2012), two years after the publication of the James et al. (2010). We acknowledge this new publication and accept the updated terminology. We agree that the outer surface we originally called the "organic protein layer" is actually a heavily mineralized layer called the squamulae. We remove this layer mechanically to access the inner part of the scale (see Figure 1). This inner part is known as elasmodin and not "dense lamellar bone" as described in James et al. (2010). This is the part of the scale that is sampled for ${ }^{14} \mathrm{C}$ (Figure 2).

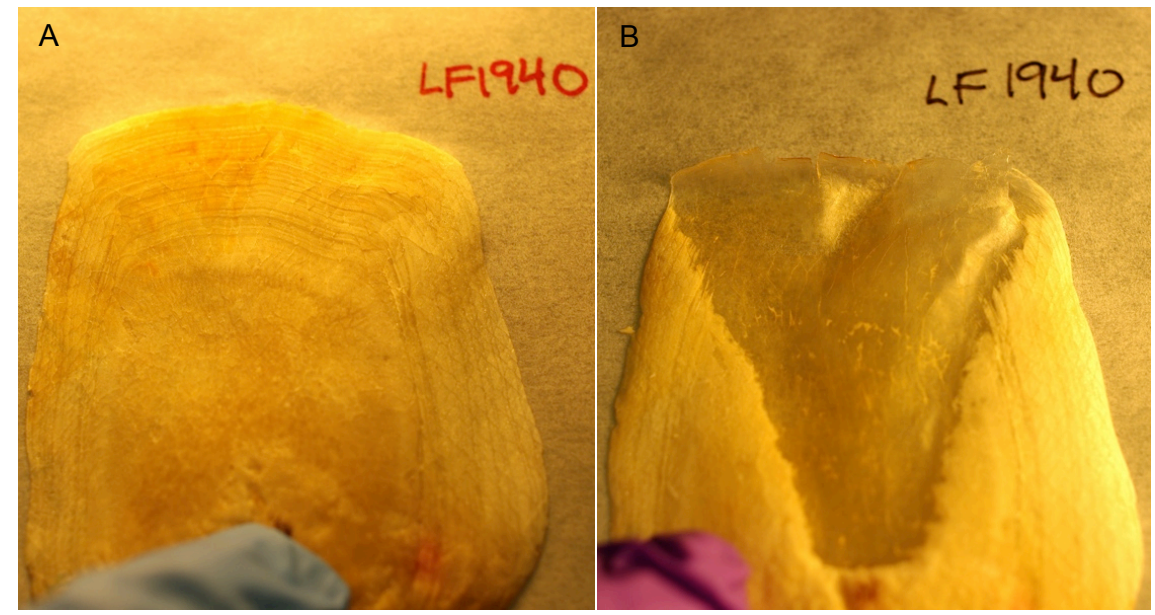

Figure 1 (A) Lungfish scale before removal of squamulae (heavily mineralized layer); (B) Lungfish scale after squamulae removal.

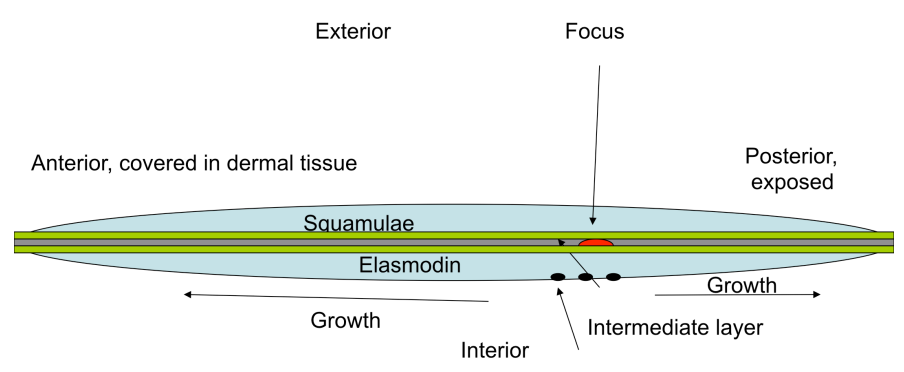

Figure 2 Diagram of lungfish scale. Prior to sampling for ${ }^{14} \mathrm{C}$, we remove material from the posterior (squamulae) and remove a small amount from the elasmodin, leaving the thin $(\sim 1 \mathrm{~mm})$ green and gray section that we sample.

1. Research School of Earth Sciences, The Australian National University, ACT, Australia. Corresponding author. Email: Stewart.Fallon@anu.edu.au.

2. Natural Resources and Mines, 16-32 Enterprise St, Bundaberg, QLD Australia.

3. seqwater, 117 Brisbane Street, Ipswich, QLD, 4305 Australia.

4. Fisheries Queensland, Department of Agriculture, Fisheries and Forestry, QLD, Australia. 
Kemp's second issue relates to the use of $\mathrm{NaOH}$ on the elasmodin. The weak $\mathrm{NaOH}$ referred to in James et al. (2010) was $0.01 \mathrm{M} \mathrm{NaOH}$. This was utilized for a light cleaning. This step has been subsequently abandoned (no benefit or detriment observed, unpublished data) and only MilliQ ${ }^{\mathrm{TM}}$ water is used to soften the elasmodin to make it easier to cut. To date, there is no evidence to support the notion of dilute $\mathrm{NaOH}$ leaching the material. The question of bacterial degradation of the elasmodin suggested by Kemp has not been proven. All samples currently recovered are frozen after collection.

The last issue relates to the actual material and locations sampled. In James et al. (2010) and subsequent research (unpublished), we mechanically clean the squamulae (heavily mineralized material), exposing the elasmodin (Figure 1). We then turn the scale over and remove material from the bottom of the elasmodin, leaving the center green/gray material as per Figure 2. This leaves us with a very thin $(<1 \mathrm{~mm}$ thick) deposit of elasmodin; we then remove consecutive narrow strips starting on the outside (most recent growth, Figure 2) back toward the focus or primordium. This provides as clear a time series as we can obtain. Figure 3 shows the ${ }^{14} \mathrm{C}$ data when the outer squamulae is not removed compared to the ${ }^{14} \mathrm{C}$ data after our mechanical cleaning. Figure 3 clearly shows the effect of the thickening squamulae on the ${ }^{14} \mathrm{C}$ data. We fully acknowledge that this technique would cause a reduction in the atmospheric ${ }^{14} \mathrm{C}$ signature captured in the scale because a small mix of years is sampled. However, this technique demonstrated that the trend in the ${ }^{14} \mathrm{C}$ values across the scale could be matched to the atmospheric bomb curve (see Figure 2; James et al. 2010). Furthermore, it is not the absolute ${ }^{14} \mathrm{C}$ value that is important but where the inflection points occur in the scale, so although the ${ }^{14} \mathrm{C}$ value may not have been exact, the growth could be shown since atomic testing. James et al. (2010) does not claim to use the absolute values but used the technique along with the von Bertalanffy equation to provide an accurate age.

Figure $3{ }^{14} \mathrm{C}$ data (percent modern carbon) vs. distance from outer edge of scale. The same lungfish scale sampled twice, once without full mechanical cleaning (open squares), the other plot shows full mechanical cleaning and the bomb curve (solid circles).

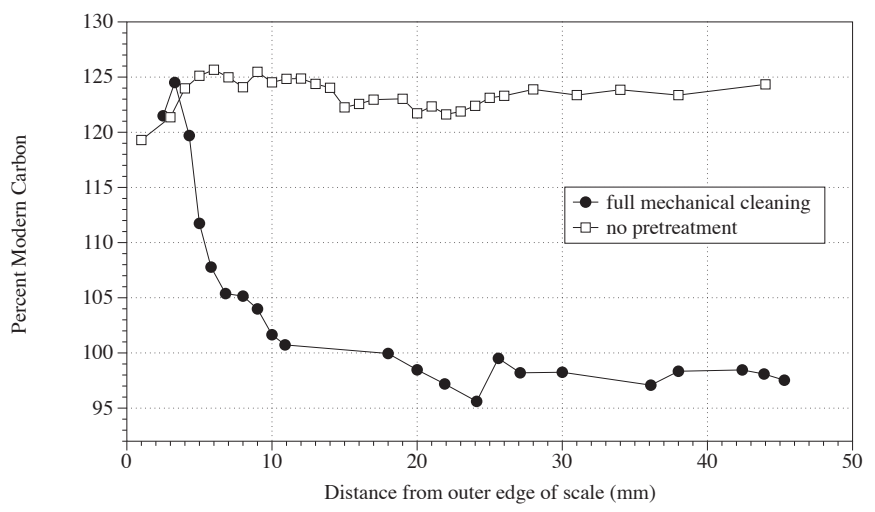

In summary, the new information gleaned from Kemp (2012) after the publication of James et al. (2010) has provided the authors with a better appreciation of the scale structure in order to refine the technique and further interpret the data. The improved technique has now been tested and verified using recaptured specimens (unpublished data). Currently, all published work that has been cited on $N$. forsteri scales has been limited to immature lungfish and this research is the first to address adult specimens. Not only will this technique provide a dependable way to age lungfish, but it will be the tool used to produce the first estimate of age structure of wild lungfish populations with the aim of improving the future for this threatened species.

\section{REFERENCES}

James KM, Fallon SJ, McDougall A, Espinoza T, Broadfoot C. 2010. Assessing the potential for radiocarbon dating the scales of Australian lungfish (Neoceratodus forsteri). Radiocarbon 52(3):1084-9.

Kemp A. 2012. Formation and structure of scales in the
Australian lungfish, Neoceratodus forsteri. Journal of Morphology 273(5):530-40.

Kemp A. 2015. Assessing the age of wild lungfish: comments on James et al. (2010). Radiocarbon 57(1):193-4. 